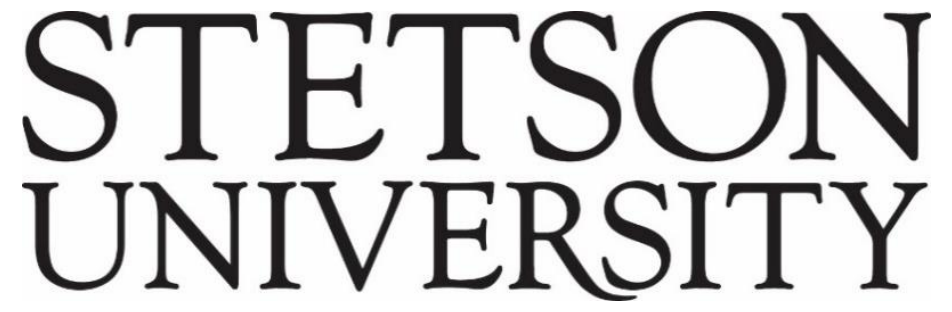

Voices of Reform: Educational Research to Inform and Reform

Volume $3 \bullet$ Issue $1 \bullet$ Article 5

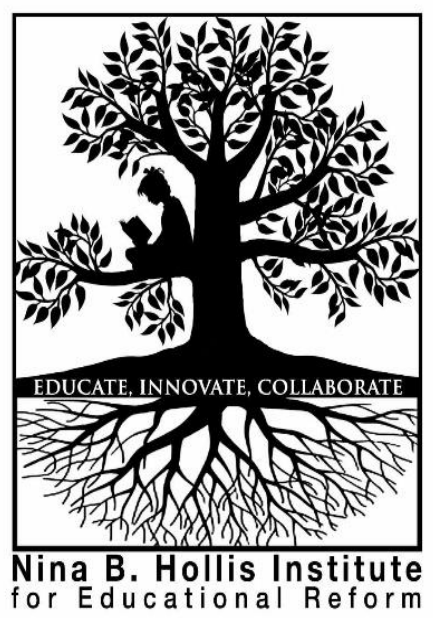

May 2020

\title{
Swamping Errors: A Florida Postmortem for High School Graduation Rate Proxies
}

David G. Martinez

University of South Carolina

Sherman Dorn

Arizona State University

Follow this and additional works at: http://www.voicesofreform.com

Recommended Citation

Martinez, D. \& Dorn, S. (2020). Swamping errors: A Florida postmortem for high school graduation rate proxies. Voices of Reform, 3(1), 91-121. Retrieved from https://www.voicesofreform.com/article/12774-swamping-errors-aflorida-postmortem-for-high-school-graduation-rate-proxies doi: 10.3623/3.00007

http://dx.doi.org/10.32623/3.00007

Revisions

Submission date: August $13^{\text {th }}, 2019$

$1^{\text {st }}$ Revision: October $23^{\text {rd }}, 2019$

Acceptance: November $14^{\text {th }}, 2019$

Publication date: May $1^{\text {st }}, 2020$ 


\title{
Swamping Errors: A Florida Postmortem for High School Graduation Rate Proxies
}

\author{
David G. Martinez ${ }^{1}$ \\ Sherman Dorn ${ }^{2}$ \\ ${ }^{1}$ Department of Educational Leadership and Policies \\ University of South Carolina, United States \\ dgmar@mailbox.sc.edu \\ ${ }^{2}$ Division of Educational Leadership and Innovation \\ Arizona State University, United States \\ sherman.dorn@asu.edu
}

\begin{abstract}
In its regulatory attention on school-level graduation, the Every Student Succeeds Act (ESSA) continues what is historically a federal effort to define graduation and dropping out. These efforts rely on methodology which may not accurately represent the measured outcome. The purpose of this research article is to examine the historical accuracy of graduation-rate proxies commonly used before the federal definition of the adjusted-cohort graduation rate (ACGR) in 2008. Our findings suggest the historical methodologies used to measure graduation have been less sensitive than necessary to estimate district-level graduation accurately. This complicated relationship should give policymakers pause about over-reliance on insensitive measures believing that "better than nothing" is plausibly accurate. We conclude with implications for policy and recommendations for research.
\end{abstract}

\section{Keywords}

dropout rate, educational policy, measurement

\section{Introduction}

In its regulatory attention on school-level graduation, the Every Student Succeeds Act (ESSA) continues what is historically a federal effort to define key measures around graduation and dropping out, solidified by the No Child Left Behind Act of 2001 (NCLB). NCLB ushered in an era of high-stakes accountability at the federal level with mechanisms that mandated the identification of districts and schools not meeting specific achievement markers defined as adequate yearly progress (AYP). While ESSA eliminates many of the most controversial features of NCLB, the effort to implement accountability measures continues, reflecting the political 
urgency of specific measures of educational success (both achievement and attainment). Of key achievement metrics, the high school graduation rate is easily consumable, a fundamental indicator of a school's success or failure. The graduation rate reflects the potential for long-term economic success and social mobility (Pinkus, 2006; Rumberger, 2011; Webb, 2016). Without a high school diploma or equivalent, adults are less likely to vote, attend college, and obtain/retain employment (Nover, Godsay, Kirby, \& Kawashima-Ginsberg, 2010; Zaff et. al., 2016). Thus, low measures of the completion of high school leads to concern and political attention focused on schools with lower graduation rates, as well as practices and policies that seek to meet the needs of those students least likely to graduate (Rumberger, 2011).

For most of this decade, the federal department of education has touted rising official graduation rates in the country as a whole, reaching 85\% for the class graduating on time in 2016-17 (McFarland et. al., 2019). Despite this apparent success, graduation gaps continue to exist between middle and high-income students, on the one hand, and low-income students of diverse race, culture, language, and national origin, on the other. Nationally, the 2017 graduation rate for lowincome students was $78.3 \%, 6.3 \%$ lower than the national average of $84.6 \%$, and $12.1 \%$ lower than non-low-income students (Atwell, Balfanz, Bridgeland, \& Ingram, 2019). These graduation rate differences persist when examined by race. McFarland et. al. (2019) reported a LatinX graduation rate of $80 \%$ and an African American graduation rate of $78 \%$, in contrast with the graduation rate of Caucasian students, 89\%. Fundamentally, students marginalized by structural racism and poverty continue to lag, stifling opportunities upstream through the educational pipeline and the economy. Stakeholders have struggled to implement practices limiting the extent of dropping out in marginalized communities (Dillard, 2000; Garcia \& Mayorga, 2018; Milner, 2007; Stanfield, 1995). Communities that require much more detailed information than standard metrification provides (Covarrubias, 2011; Dillard, 2000; Milner, 2007; Stanfield, 1995). Stakeholders at all levels seek improvement, but to create viable solutions, the metrics must accurately reflect granular information about the educational community (Gilborn, Warmington, \& Demack, 2018; Khalifa, Jennings, Briscoe, Oleszweski, \& Abdi, 2014; Lopez, Erwin, Binder, \& Chavez, 2018).

The specific policy-driven mechanism matters in the development of measures. NCLB required states to measure graduation, at first with no standard federal metric, and state measures varied dramatically for the first decade of NCLB's authority (Greene \& Foster, 2003; Rumberger, 2011). Only slowly did states, districts, and schools move toward a common method of calculating graduation, after the enactment of a standard definition in 2008 federal regulations. These new federal regulations required the use of a standardized rate based on an adjusted ninth-grade cohort, which has now become known as the adjusted-cohort graduation rate [ACGR] (Improving the Academic Achievement of the Disadvantaged, 2008). While ESSA continues the use of ACGR as a methodologically improved uniform metric of graduation, the ACGR did nothing to curb graduation gaps that persist across communities, the rhetoric surrounding struggling schools, nor the negative dialogue manufactured by previous graduation metrics.

Over the last two decades, Balfanz and colleagues have focused on school-level graduation differences in identifying what his research center publicly labels as dropout factories (e.g., Balfanz \& Legters, 2004; Balfanz, Legters, \& West, 2007). Discussion among key reform 
advocates led to recommendations by the National Governors Association spurring the 2008 federal regulation (Task Force on State High School Graduation Data, 2005). In contrast with controversy over achievement testing, mandates, or the definitions proposed to qualify highquality teachers, public attention on graduation has reinforced federal authority and concern. ESSA attenuated both the definition and consequences of accountability metrics across the United States; however, ESSA requires states to continue to measure ACGR as one of the mandated metrics of school-level success or failure, and thus a trigger of state intervention (U.S. Department of Education, 2017). This raises concerns over the epistemic implications of quantifying student achievement, graduation or otherwise, and the ability of metrification to capture the nuances of schooling in a manner that leads toward improvement (Garcia, Lopez, \& Velez, 2018).

The history of the graduation-rate measure within federal K-12 accountability provides an opportunity to look at the graduation rate as an example of a concept with proxy measures. In at least one state, the department of education not only published district-level graduation measures using ACGR since being required by federal regulation but recalculated district-level graduation measures year by year for the decade before the federal regulation was implemented. This time series of data allows us to compare various proxy measures to the federal graduation rate. The purpose of this research article is to use this state to examine the historical accuracy of the oftcited graduation-rate proxies (i.e., ACGR, $8^{\text {th }}$ and $9^{\text {th }}$ grade Boston College Rates [BCR-8 and BCR-9], Adjusted Freshman Graduation Rate [AFGR], Cumulative Promotion Index [CPI]) through a single state study; Florida. Florida's local public school districts are countywide (charter schools and university laboratory schools are excluded from this analysis). As with many other states, Florida's Department of Education now publishes graduation data using the federal definition of adjusted-cohort-based graduation rates. Going beyond federal mandates to publish current rates, Florida has also published a time series of county-level graduation rates from the spring 2001 graduating year to 2013 using the new federal rate and Florida's longitudinal student database. The existence of this time series data allows the comparison of the proxy measures used in the last decade or more to the new federal rate.

Through our study, we question the ability of oft-cited graduation-rate proxies to identify low or high-graduation districts given localized nuances due to district scale, socioeconomic conditions, or financial resources in the county or school district. The strategy for our analysis is a post-mortem comparing graduation-rate proxies to the new federal definition, using Florida county-level reporting. We compare graduation-rate proxies because the history of concerns over high school graduation is replete with efforts to measure graduation as part of the strategy for intervening in school failure through top-down policy implementation. This process which does not account for idiosyncratic nuances necessary to implement long term solutions within those schooling communities. Furthermore, almost 10 years after NCLB first implemented the ACGR graduation gaps persist (U.S. Department of Education, 2017). The theory of transparent measurement in accountability is that stakeholders require valid metrics that can provide granular information school- and district-specific graduation rates, in this case. Given the extent to which policy relies on proxies - including graduation rates before a standardized measure - we explore the degree to which these graduation-rate proxies methodologically function as accurate, trustworthy metrics. 


\section{Literature Review}

The high school graduation rate has both political and practical significance, gauging how well society is educating its citizenry (e.g., Heckman \& Lafontaine, 2010; Rumberger, 2011). Levin (2009) argues a high school education provides personal independence, productivity, and reduced social welfare costs. In the twentieth century, increasing graduation rates boosted U.S. economic growth (Dorn, 1996; DeLong, Goldin, \& Katz, 2003; Heckman \& Lafontaine, 2010; Goldin \& Katz, 2009). Between roughly 1970 and the early 2000s, graduation stagnated, and in contemporary compulsory education, there exists little explanation for the recent increases requiring further investigation (Murnane, 2013). In this section, we discuss literature on graduation rate estimates. We then describe relevant policy debates related to the intersection of metrification and practical improvement.

\section{Graduation Rates}

The No Child Left Behind Act increased attention toward graduation levels, in part through requiring their use in the rating of schools (Swanson, 2004). This mandate followed a 50-year history of efforts to reduce dropping out and measure student persistence (e.g., Dorn, 1996). In that historical context, a standard national graduation rate represents a significant technical advance and a caution about managing critical education phenomena through technocratic means. The need: educational policy that could potentially close the achievement gap between middle class white and marginalized students of color. The consistent technical urge: measure today what is possible to measure. This required more than 40 years and over those decades, researchers have struggled with the challenges of identifying and analyzing high school drop-out, including the use of various graduation rate proxies (e.g., Rumberger, 1987, 2011).

Before standardizing a graduation rate proxy, the National Center on Education Statistics published three separate graduation measures: a population-based rate measuring the percentage in a population completing high school; a school-based percentage of students who graduated in specific years; and a proxy population-based measure, the ratio of high school graduates to the population aged 17 in any particular year (e.g., Kaufman, Alt, \& Chapman, 2004). The first iteration of an official NCLB-era graduation rate used the Adjusted Freshman Graduation Rate (Seastrom et. al., 2006), the ratio of graduates in a year to the average of eighth, ninth, and tenthgrade enrollments in the years where an on-time graduate would have attended those grades (Stillwell \& Sable, 2013). Miao and Haney (2004) proposed a ratio of graduates to eight-grade or ninth-grade enrollment from five or four falls before the graduation spring (the Boston College Rates, BCR-8 and BCR-9 respectively); Swanson (2004) proposed the Cumulative Promotion Index (CPI), a product of four ratios of enrollment and graduation around the spring of a graduation year. The collection and aggregation of data that are sensitive to methodological choice limited the existing graduation rate proxies leading toward further exploration and relevant policy debate (Heckman \& LaFontaine, 2010; Murnane, 2013).

Relevant Policy Debates

Graduation measurement validity. Graduation rate measurement through Census surveys enables calculation of a high school completion rate by estimating the percentage of persons in a 
household currently not attending any secondary school or that have completed a high school diploma. This method of data collection is wrought with issues often relying on one member of each household as a sole respondent, raising concerns over respondent accuracy (Heckman \& LaFontaine, 2010; Murnane, 2013). One sees this in the U.S. Department of Education report Trends in High School Dropout and Completion Rates in the United States: 1972-2009 (Chapman et. al., 2011). Researchers have also raised concerns over the Current Population Survey's exclusion of institutionalized/incarcerated individuals, as well as some members of the military (in contrast with decennial censuses or the American Community Survey) (e.g., Heckman \& LaFontaine, 2010; Murnane, 2013; Swanson \& Chaplin, 2003).

More commonly, both the U.S. Department of Education and education researchers have relied on collected administrative data. The United States Department of Education National Center for Educational Statistics (NCES) has made this process easier by creating the Common Core of Data (CCD). The CCD provides cross-sectional data from each district through states but does not capture transitions such as school transfers or dropping out (Murnane, 2013). To accurately measure graduation, however, it is imperative the collection mechanism accurately record every student that transfers in and out of the locality accounting for migration (Biesta, 2015); high in areas with low graduation (Murnane, 2013). This requires a data infrastructure schools simply do not have, and administrators desperate to meet national standards may under-count dropouts by allowing for amorphous student migration count and data collection. For example, accepting dropouts' claims of transferring to another school without validating the claim, leading to an inherent validity challenge with the ACGR.

The ACGR itself is acutely indifferent to in-out transfer patterns, based solely on the last school of attendance. The ACGR calculation is based on a cohort derived from attendance attribution; a student is assigned to the last school they attended regardless of time. Therefore, a student on track to graduate from school $X$ in 4-years can transfer to school $Y$ at the beginning of year-4, and their on-time graduation is counted only toward school $Y$. The ACGR has no mechanism to account for these localized nuances. Graduation rate metrics also require long lag times for measurement, and this plausibly impacts the accuracy of the outcome given the challenges with in-out transfer patterns mentioned above. These complications inform the validity of data and statistical measures, inclusive of their ability to infer fact from numeracy (Elliot \& Murayama, 2008). Finally, inclusive of data collection/ aggregation and methodology challenges, there is doubt due to measurement, leading toward improvement, data privacy concerns, and the assumption of statistical neutrality.

Can measurement improve attainment. The critique of measurement is nothing novel in the greater landscape of educational improvement. These critiques stem from different views on data collection and analysis, how results are reported, and efforts toward improvement (Blalock, 1982; Borden \& Young, 2008; Shadish, Cook, \& Campbell, 2002; Cronbach, 1988; Ebel \& Frisbie, 1991). The adoption of a uniform federal definition of graduation is rooted in the need to accurately measure graduation in order to create solutions that impact those communities with the highest graduation gaps. Policymakers have struggled however, to craft and implement policy curbing high school drop-out in marginalized communities. Balfanz (2004) and colleagues have operated on the assumption that identification of individual "dropout factories" is the best mechanism for 
improving secondary attainment, ushering in a desperate search for proxies leading to the standardized cohort-based measure, matching the continuation of federal policy requiring graduation rate measurement through state accountability systems (Balfanz \& Legters, 2004; ESSA, 2015; Klein, 2015). We might call this the metric assumption of accountability policy: measurement is a necessary antecedent for improvement. This metric assumption is not a consensual position, as Zaff et. al. (2016) question whether measuring graduation helps address marginalized student disparity. Ultimately the answer is no. Achievement metrics, and specifically the graduation rate, work to identify a broad reality, but have no implications in diagnosis of the challenges which lead to the symptom. Furthermore, there are major concerns over how data and privacy intersect to impact change, and the robustness of achievement metrics to capture nuances that create symptomatic gaps in achievement.

Privacy and educational system indicators. With the rise of "big data," an explicit debate has opened up in the tension between privacy and public interest (e.g., Lane, Stodden, Bender, \& Nissenbaum, 2014). Lane et. al. illustrated these debates assuming value in such data, neglecting an escape from their concerns? The proxy graduation rates proposed in the 2000 s needed aggregate information published by states, through the CCD, and data that described cross-sections of students at specific points in time, pulling multiple information from multiple sources. In contrast, the new federal rate requires longitudinal tracking of individual students, following cohorts that bear tenuous connections to the cross-sectional aggregate data.

The impact of neutral data assessment. Metrification assumes a net neutrality in measurement, but the nature of the statistical understanding encompassing race impacts quantitative representation (Garcia \& Mayorga, 2018; Stovall, 2013; Zuberi, 2001). NCLB reified metrification in order to justify policy priorities, but the discourse extends beyond metrification toward a "superficial understanding of racism" that "perpetuate white supremacy" and achievement gaps (Garcia \& Mayorga, 2018, p. 236; Gillborn, 2010, p. 4). As outlined in previous sections, lowincome students continue to trail not only the national trend, but also their wealthier peers (Atwell, Balfanz, Birdgeland, \& Ingram, 2019; DePaoli et. al.et. al., 2015; Stetser \& Stillwell, 2014). Furthermore, these demographic graduation gaps are concentrated in schools with a higher enrollment of historically marginalized students of color (Carpenter \& Ramirez, 2007; Lee, Cornell, Gregory \& Fan, 2011). The understanding of these student-centered nuances is not devoid of bias, and the language used to justify proposals for improvement are grounded in the perception of the group (Haberman, 2000; Milner, 2007). The attempt at comparative uniformity does nothing to curb the symptom of social disparity and is threatening to those communities of need, embedding assumptions of the social processes leading to symptomatic achievement gaps (Gillborn, 2010; Ladson-Billings \& Tate, 1995). Finally, given these complicated intersections, valid identification of the challenge, through nuanced measurement is required, in order to move toward improvement. The historical measures have only solidified the negative rhetoric centered on marginalized student populations, and done little to curb barriers leading to the symptom (Garcia, Lopez, \& Velez, 2018; Gillborn, Warmington, \& Demack, 2018; Maguire, Gewirtz, Towers, \& Neumann, 2019). This study continues to catalyze the discourse, questioning the reliability of these graduation-rate proxies, by comparatively analyzing their methodological utility. 


\section{Methods}

The analysis process was conducted in three stages. We began by calculating the graduation rate proxies described below, with enrollment and graduation figures publicly available through the Common Core of Data or the state of Florida (for diplomas issued for selected years). In the second phase, we compared the proxy graduation rates to the federal adjusted-cohort graduation rate (ACGR) for Florida's county-wide school districts for graduation years 2003 through 2013, with simple measures (correlations, means, medians, and standard deviations) to compare the proxies with the official federal graduation rate with Florida county-level data (Florida's 67 local school districts are contiguous with the state's counties). We followed up with residual analysis to identify possible ways that the proxy measures may have distorted the identification of low or high graduation school districts.

\section{Graduation Rate Measures}

The Florida Department of Education has published federal graduation rates for all graduates in the spring of years 2001 through 2013, including retroactive publication of ACGR rates (e.g., Florida Education Information \& Accountability Services, 2015). We calculated the proxy measures from official enrollment and academic (standard) diploma measures according to the published definitions of Miao and Haney (2004) for the Boston College Rates (based on both $8^{\text {th }}$ and $9^{\text {th }}$-grade enrollment-BCR-8 and BCR-9), Seastrom et. al. (2006) for the Adjusted Freshman Graduation Rate (AFGR), and Swanson (2004) for the Cumulative Promotion Index (CPI).

\section{Boston College Rates (BCR)}

Miao and Haney (2004) proposed a simple ratio of graduates in the graduating year's spring to the enrollment of eighth-graders five autumns before (for BCR-8) or the ratio of graduates to the enrollment of ninth-graders four autumns before (BCR-9). Both BCR-8 and BCR-9 are simple to calculate for a unified district, BCR-9 simple for a four-year high school. Both can be biased by differential graduation among transfers (both in and out of a school or district) and by the effects of differential retention across grades as well as differential graduation among those retained or promoted. The commonly greater retention rate in ninth grade often leaves a ninth grade "bulge," leading to an artificially deflated BCR-9.

\section{Adjusted Freshman Graduation Rate (AFGR)}

Seastrom et. al. (2006) proposed an adjustment to crude rates to accommodate the ninth-grade bulge resulting from disproportionate retention in ninth grade in many high schools. The proposed adjustment in Adjusted Freshman Graduation Rate (AFGR) uses an average of the eighth, ninth, and tenth-grade enrollment numbers in successive years to substitute for the base enrollment in the denominator of BCR-9 — e.g., the denominator for the class of 2008 in any county would average eighth-grade enrollment in fall 2003, ninth-grade enrollment in fall 2004, and tenth-grade enrollment in fall 2005. AFGR assumes that a linear average across years is an accurate estimate of the base ninth-grade enrollment for a cohort; both different cohort sizes and different promotion rates across adjacent cohorts may leave different sizes of "second-year" ninth-graders that AFGR 
attempts to adjust for. In addition, AFGR is vulnerable to the same bias from differential graduation rates for transfer students as BCR-8 and BCR-9.

\section{Cumulative Promotion Index (CPI)}

Swanson's (2004) Cumulative Promotion Index (CPI) is not labeled a graduation rate. It is the chained product of one-year ratios, each term dividing the enrollment in one grade in a single autumn by the enrollment in the prior year, with the final product being the ratio of graduates to twelfth-grade enrollment in the prior autumn. CPI is thus a proxy period measure rather than a longitudinal proxy measure, drawing from enrollment and graduation data from two successive years to assert a general condition of student promotion and graduation between the two autumns. One can more easily understand the CPI as an imaginary cohort of ninth graders starting in the first autumn. Those who are in the school the next autumn are all put into an imaginary time machine and start as tenth graders the previous autumn, subject to that year's ratio. The next autumn's (surviving) eleventh graders move back to start eleventh grade in the previous autumn, and the surviving twelfth graders in this imaginary cohort are likewise returned to start their senior year in the first autumn. In equation form,

$C P I(t)=\frac{N_{t}^{10}}{N_{t-1}^{9}} \frac{N_{t}^{11}}{N_{t-1}^{10}} \frac{N_{t}^{12}}{N_{t-1}^{11}} \frac{G_{t}}{N_{t-1}^{12}}$,

where CPI is the Cumulative Promotion Index for year t, $N_{t}^{10}$ is the enrollment in tenth grade in the fall of year $\mathrm{t}$, and likewise for all other terms except $G_{t}$, the number of graduates (with academic diplomas) in the spring of year $\mathrm{t}$.

As with all measures discussed earlier, CPI is vulnerable to differential "survival" rates for transfer students (again, both in-transfers and out-transfers), and as with BCR-9, there is no attempted adjustment for the ninth-grade bulge - in most cases, that first product (from ninth to tenth enrollment) is likely to understate the true measure of CPI assuming perfect knowledge of a starting ninth-grade cohort.

\section{Adjusted Cohort Graduation Rate (ACGR)}

As defined in federal regulations (Title I-Improving the Academic Achievement of the Disadvantaged, 2008), the adjusted-cohort graduation rate (ACGR) is a longitudinal measure "defined as the number of students who graduate in four years with a regular high school diploma divided by the number of students who form the adjusted cohort for that graduating class" (34 C.F.R. $\$ 200.19(b)(i)(A))$. The spirit of the federal regulation is that ACGR is a true longitudinal measure. If there is accurate longitudinal tracking, bias from retention is excluded once a student matriculates for the first time in ninth grade. ACGR includes any differential graduation among in-transfers and excludes differential graduation among out-transfers; that is a political judgment of where responsibility for student success in high school lies. One source of potential bias is differential administrative tracking of students labeled as out-transfers; if there is no auditing of student records, it could be possible that students who leave high school without enrolling in another school are mislabeled as out-transfers and excluded from the cohort rate instead of being counted as non-graduates of the adjusted cohort. 


\section{Residual Analysis}

In addition to examining simple measures such as correlations between proxies and the published graduation rates for each county and year, we analyzed the residuals - simple differences between the published ACGR graduation rate and the prediction of the published ACGR using just the proxy rate(s) for an individual country-year combination as the independent variable (i.e., a bivariate-regression residual). The driving question was whether proxy graduation rates not only predicted graduation inaccurately (a measure-specific bias) but whether the identification of districts as low or high-graduation was distorted by important factors such as the size of districts, socioeconomic conditions in Florida's counties, or financial resources in the county or school district. To test this theory the linear model residuals of our four comparisons (i.e., BCR-8: ACGR, BCR-9: ACGR, AFGR: ACGR, CPI: ACGR) were fitted against district (county) enrollment data, racial demographic data, as well as property values, school revenue provided by federal, state and local sources, total revenue, and total expenditures for the 2005-2006 school year. This year was chosen as the peak of the economic cycle before the 2007-2009 recession and thus reflective of persistent county-level differences in socioeconomic conditions.

\section{Data Sources}

We obtained racial demographic, property values, school revenue provided by federal, state and local sources, total revenue, and total expenditures, as well as time-series data of enrollment, graduation diploma counts, and the official federal ACGR for this study from the following sources:

(1) National Center for Education Statistics Common Core of Data 1998-2013 (CCD), including 8th-12th grade enrollment, academic (standard) diplomas awarded through spring 2009, racial demographic and financial characteristics (National Center for Education Statistics, 2015).

(2) Florida Department of Education, for 2009-2013 reporting of Florida standard diplomas awarded, with 2009 used as an overlap year to check diploma data from the different sources (Florida Education Information \& Accountability Services, 2015).

(3) Florida Department of Education, for the 1998-2013 Florida ACGR as calculated using the federal calculation for graduation (Florida Education Information \& Accountability Services, 2015).

Florida recalculated and published graduation rates using the new standardized federal definition for cohorts preceding the first reporting year for the federal definition, 2010-2011. For academic diplomas since 2009, the analysis used the Florida Department of Education 2009-2013 reporting of Florida standard diplomas awarded, with 2009 used as an overlap year to check diploma data from the different sources (Florida Education Information \& Accountability Services, 2015). The BCR-8, BCR-9, AFGR, and CPI for 2002-2009 were calculated using the definition for standard diplomas, through the common core of data (CCD). These same measures were calculated for 
2009-2014 using Florida's reported and defined standard diplomas through the Florida Education Information and Accountability Services.

\section{Results}

There continues to exist a body of research that focuses on the national graduation rate as an accurate measure of educational success (i.e., DiPaoli et. al., 2016). While this empirical body is extremely valuable, there has yet to exist a cohesive body of knowledge that can determine the accuracy of graduation rate proxies often cited in these reports. This empirical analysis is an attempt to unpack this space and add some clarity to the graduation rate dilemma. We do so by analyzing not only the accuracy of these proxies to measure actual graduation rates, and then examining inter-correlations. Ultimately our results indicate there is limited success of proxy measures to accurately reflect graduation in the decade before the regulatory definition of ACGR.

\section{Graduation Rate Comparisons}

We begin with summary measures; of note is the use of leading zeroes in reporting the proxy rates. This is due to a cohort graduation rates theoretical positioning between 0 and 1 , while the proxy measures are not restricted, as the next sentence indicates. Table 1 displays the summary statistics for the four graduation rate proxy measures (i.e., AFGR, BCR-8, BCR-9, and CPI), as well as the federal graduation rate (ACGR).

Table 1: Summary Statistics Graduation Measures

\begin{tabular}{lccccc}
\hline & ACGR & AFGR & BCR-8 & BCR-9 & CPI \\
\hline Minimum & .325 & 0.148 & 0.160 & 0.146 & 0.143 \\
Maximum & .954 & 1.42 & 1.53 & 1.35 & 1.45 \\
Median & .657 & 0.675 & 0.712 & 0.602 & 0.632 \\
Mean & .660 & 0.673 & 0.708 & 0.605 & 0.633 \\
SD & .100 & 0.122 & 0.135 & 0.138 & 0.147 \\
\hline
\end{tabular}

The mean official federal ACGR across all years and counties was .66, with a standard deviation of .10, and a median of .66. The mean and median proxy rates were within the range of the median and mean for other measures ranging from 0.61 (BCR-9) to 0.71 (BCR-8) for mean and 0.60 (BCR-9) to 0.71 (BCR-8) for median. The maximum absolute values for all proxy graduation rates are above 1 (or 100\%); this might well reflect misreporting, which in smaller districts might lead to extreme values. The standard deviation for the federal graduation rate was smaller than the other measures - all other standard deviations were 0.12 or higher. While the accuracy of the proxy measures was low (see below as well as Table 2 and Figure 1), at a summary level the official federal rate appears to cluster around the same region if more narrowly than the proxies.

The proxies look far less adequate when examining correlations. Table 2 displays the correlation matrix for the four graduation rate proxy measures (i.e., AFGR, BCR-8, BCR-9, and CPI), as well as against the ACGR federal graduation rate.

Table 2: Correlation Matrix Graduation Rate Measures 


\begin{tabular}{lcccc}
\hline & ACGR & AFGR & BCR-8 & BCR-9 \\
\hline AFGR & .56 & & & \\
BCR-8 & .49 & .96 & & \\
BCR-9 & .56 & .92 & .86 & \\
CPI & .50 & .85 & .80 & .86 \\
\hline
\end{tabular}

The federal graduation rate does not have a strong correlation with any of the proxy measures, though as a set the proxy measures are often strongly correlated among each other (solely as proxies). The correlations between the federal ACGR and the proxies range from .50 (with the CPI) to .56 (both AFGR and BCR-9). The BCR-8 and AFGR are the most closely correlated among the proxies, $r(923)=.96$.

Figure 1 is a set of scatterplots charting the proxies in sequence against the official ACGR. Each panel shows the individual comparison of the graduation rate measure plotted against the federal graduation and the associated correlation. The weak correlations are evident on inspection, as well as the difficulty of using any of the proxy measures to make fine-grained distinctions between individual counties in the same year or across years. 
Figure 1: Graphic Representations of the OLS Estimation Line of the Four Proxy Measures (i.e., AFGR, BCR-8, BCR-9, and CPI) against ACGR, the Federal Graduation Rate
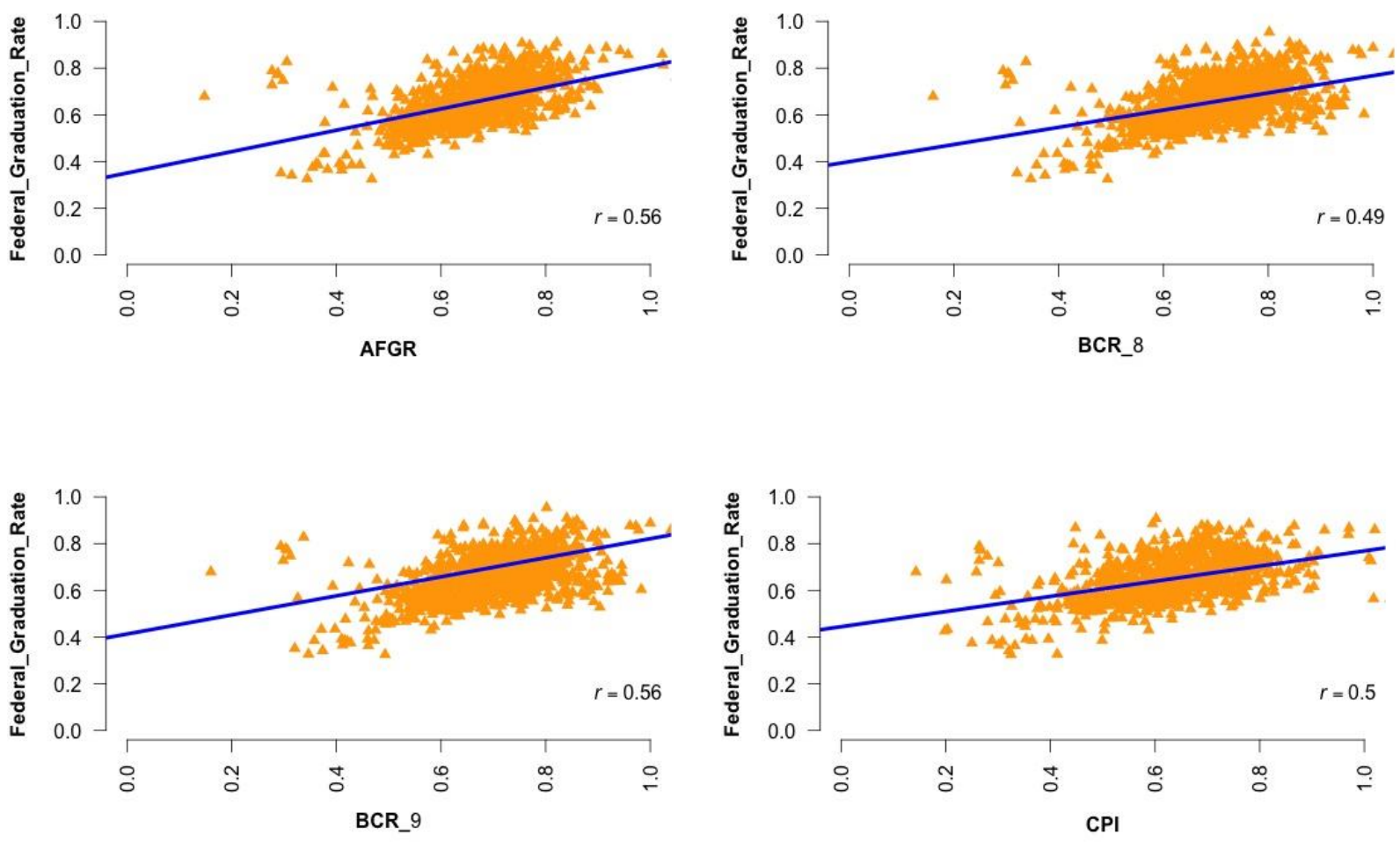

\section{Residual Analysis Results}

Beyond simple correlational analysis, we explore whether the poor accuracy of the proxy measures also incorporated any distortions associated with district characteristics; such biases would lead to distortions in which districts (or schools) were likely to receive differential consequences in accountability systems that rely on graduation rates. From the standpoint of data literacy, this type of analysis is necessary to unpack the challenges created by data and measurement error. Specifically, the ability to overpredict or underpredict graduation rates against the backdrop of variables that directly impact the operation of schools (i.e., students enrolled in the free and reduced lunch program, revenue and spending, property value, enrollment). Equity minded practitioners have the potential to mediate inequities, but they must be equipped with the data and analytic tools necessary to do so (Carpenter, 2011; Frattura \& Capper, 2007; Horsford \& Sampson, 2013). Ultimately, data has the potential to help critically conscious, equity-minded, leaders create affective change, but if the data itself is insufficient, and the measurement/ metric is insufficient, this can directly impact how critically conscious leaders confront their specific educational challenges (Aguilar, 2018; Fowler \& Brown, 2018). We thus analyzed the residuals of the ACGR 
(2008 official federal rate) predicted against the proxy measures, fiscal, and enrollment variables, to highlight potential measurement insufficiencies.

Table 3: Summary Residual Linear Model Error: ACGR against other proxies

\begin{tabular}{lcccc}
\hline & AFGR & BCR-8 & BCR-9 & CPI \\
\hline Minimum & -.10 & -0.11 & -0.14 & -0.18 \\
Maximum & .13 & 0.14 & 0.14 & 0.16 \\
Median & -.01 & 0.00 & 0.00 & 0.00 \\
Mean & .00 & 0.00 & 0.00 & 0.00 \\
SD & .05 & 0.06 & 0.05 & 0.06 \\
Skew & .25 & 0.34 & 0.20 & 0.05 \\
\hline
\end{tabular}

Table 3 provides summary statistics for the residuals. The range for the residual errors of CPI is the greatest at 0.34 . The lowest range was AFGR at 0.23 . The standard deviations for all measures were similar to AFGR and BCR-9 at 0.05 and BCR-8 and CPI at 0.06 . All proxies are positively skewed with BCR-8 having the greatest skew 0.34 and CPI having the smallest skew at 0.05 .

Examining the residual plots of the linear model of our four comparisons (i.e., BCR-8: ACGR, BCR-9: ACGR, AFGR: ACGR, CPI: ACGR) against district (county) enrollment data, racial demographic data, property values, school revenue and total expenditures for the 2005-2006 school year yielded results that were at times extremely skewed in one direction. As is clearly shown in Figure 2, the linear model is skewed toward relatively large $\mathrm{x}$-values when examining AFGR, BCR-8, BCR-9, CPI. 
Figure 2: Graphic Representation of the Four Comparative Linear Model Residuals against the total Number of Students enrolled in the Free and Reduced Lunch Program in a District
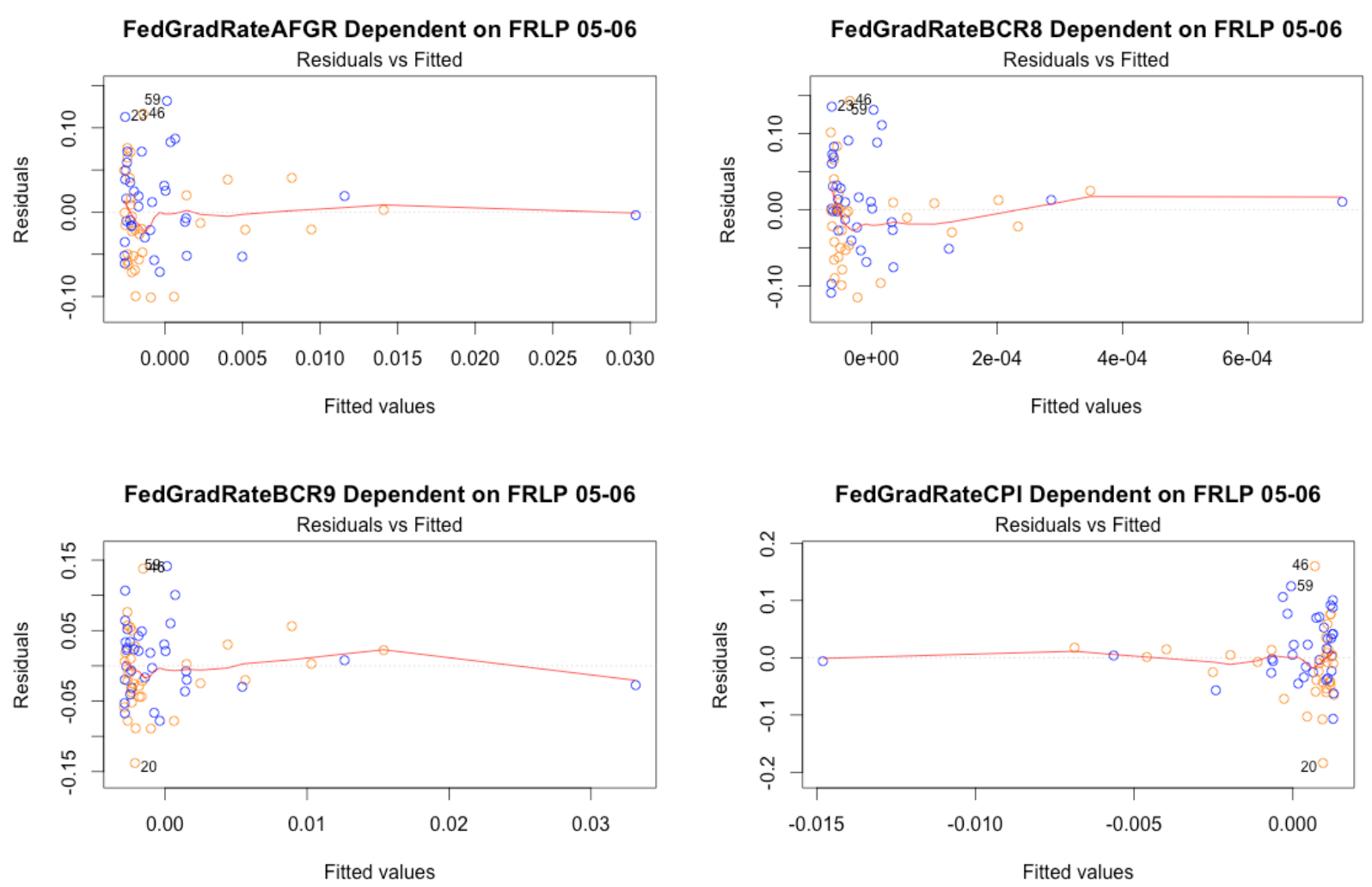

Though for the CPI plot, the outliers cross over the negative access while in the AFGR, BCR-8, and BCR-9, the outliers are in a positive direction. Figures 3 (total revenue), 4 (state revenue), 5 (federal revenue), 6 (enrollment) all exhibit these same behaviors. 
Figure 3: Graphic Representation of the Four Comparative Linear Model Residuals against the total Revenue Per Pupil
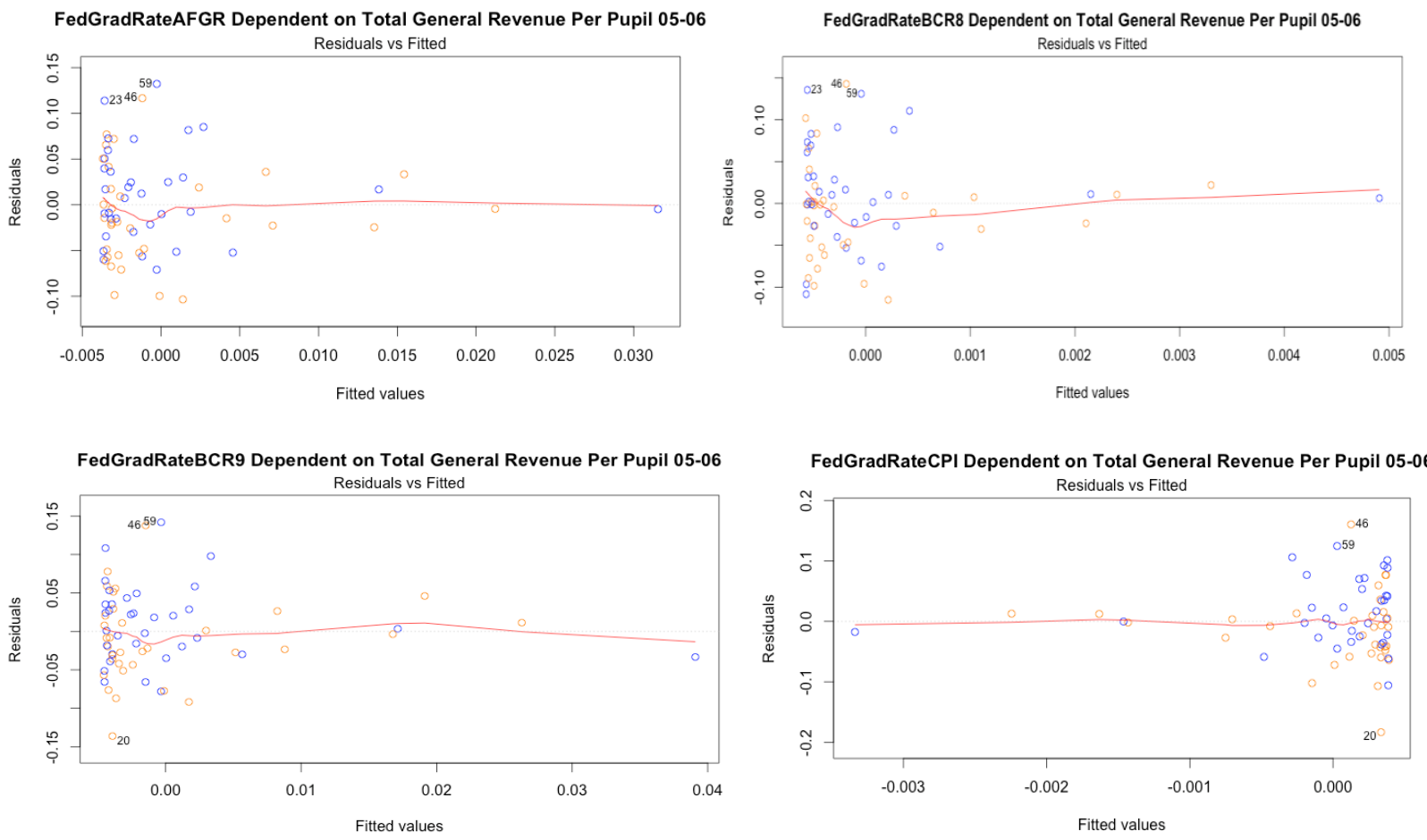
Martinez \& Dorn: Swamping errors: A Florida postmortem for high school graduation rate proxies

Figure 4: Graphic Representation of the Four Comparative Linear Model Residuals against the State Revenue Per Pupil
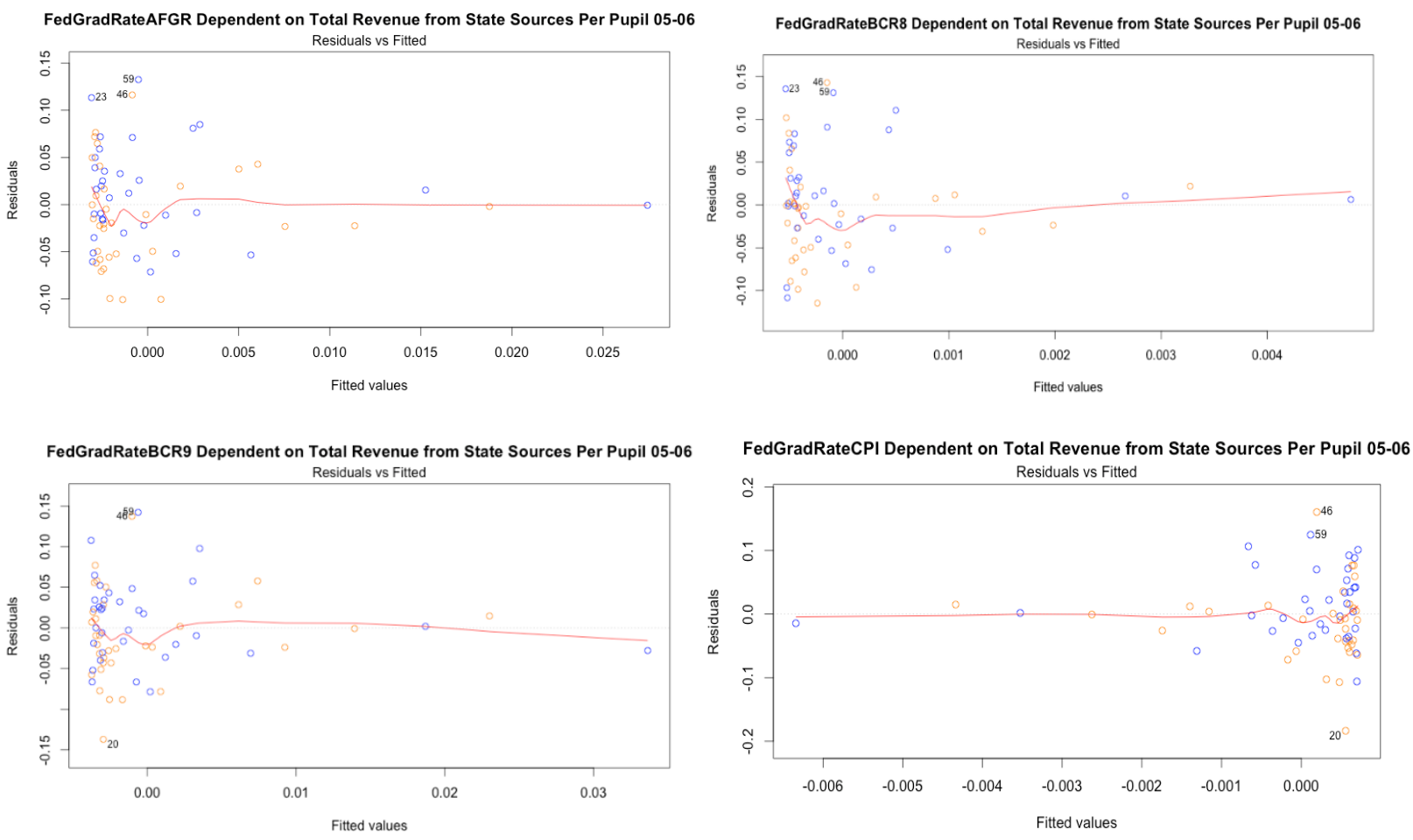
Martinez \& Dorn: Swamping errors: A Florida postmortem for high school graduation rate proxies

Figure 5: Graphic Representation of the Four Comparative Linear Model Residuals against Federal Revenue Per Pupil
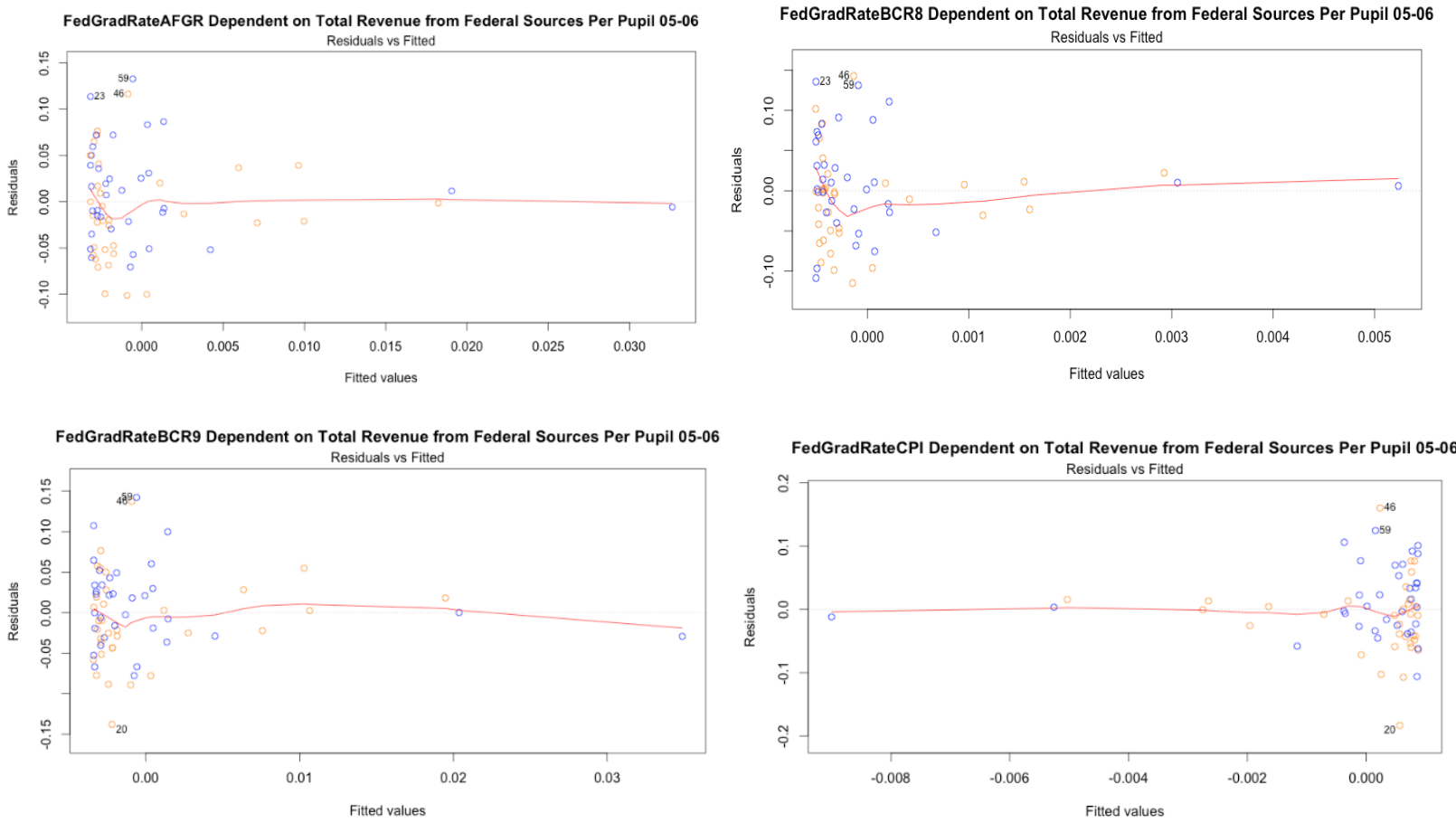
Figure 6: Graphic Representation of the Four Comparative Linear Model Residuals against Total Enrollment
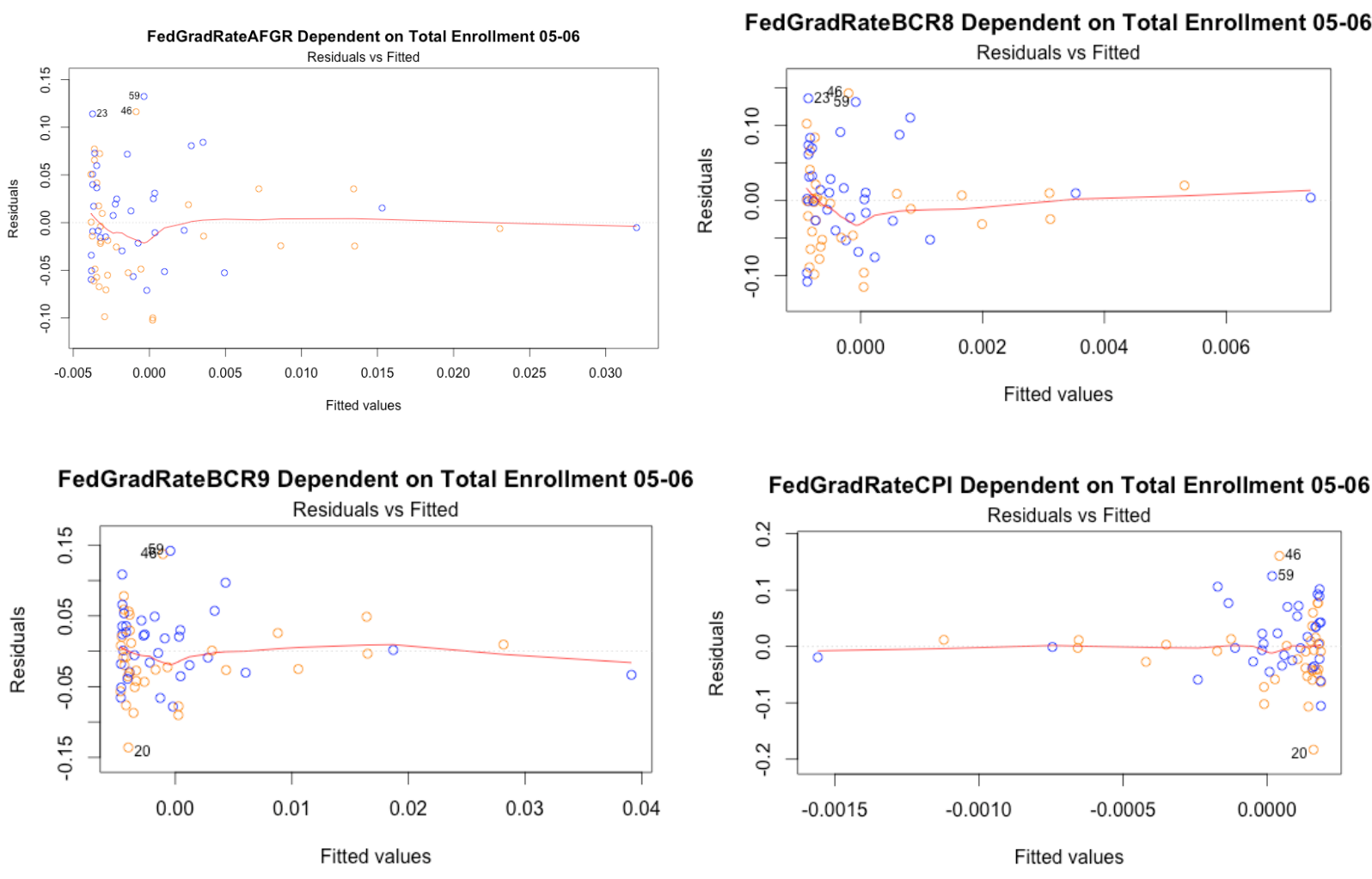

Figure 7 (total expenditures) as well as Figure 8 (race/ethnicity) do not contradict the linear assumption and are graphically random. 
Martinez \& Dorn: Swamping errors: A Florida postmortem for high school graduation rate proxies

Figure 7: Graphic Representation of the Four Comparative Linear Model Residuals against Total Expenditure Per Pupil
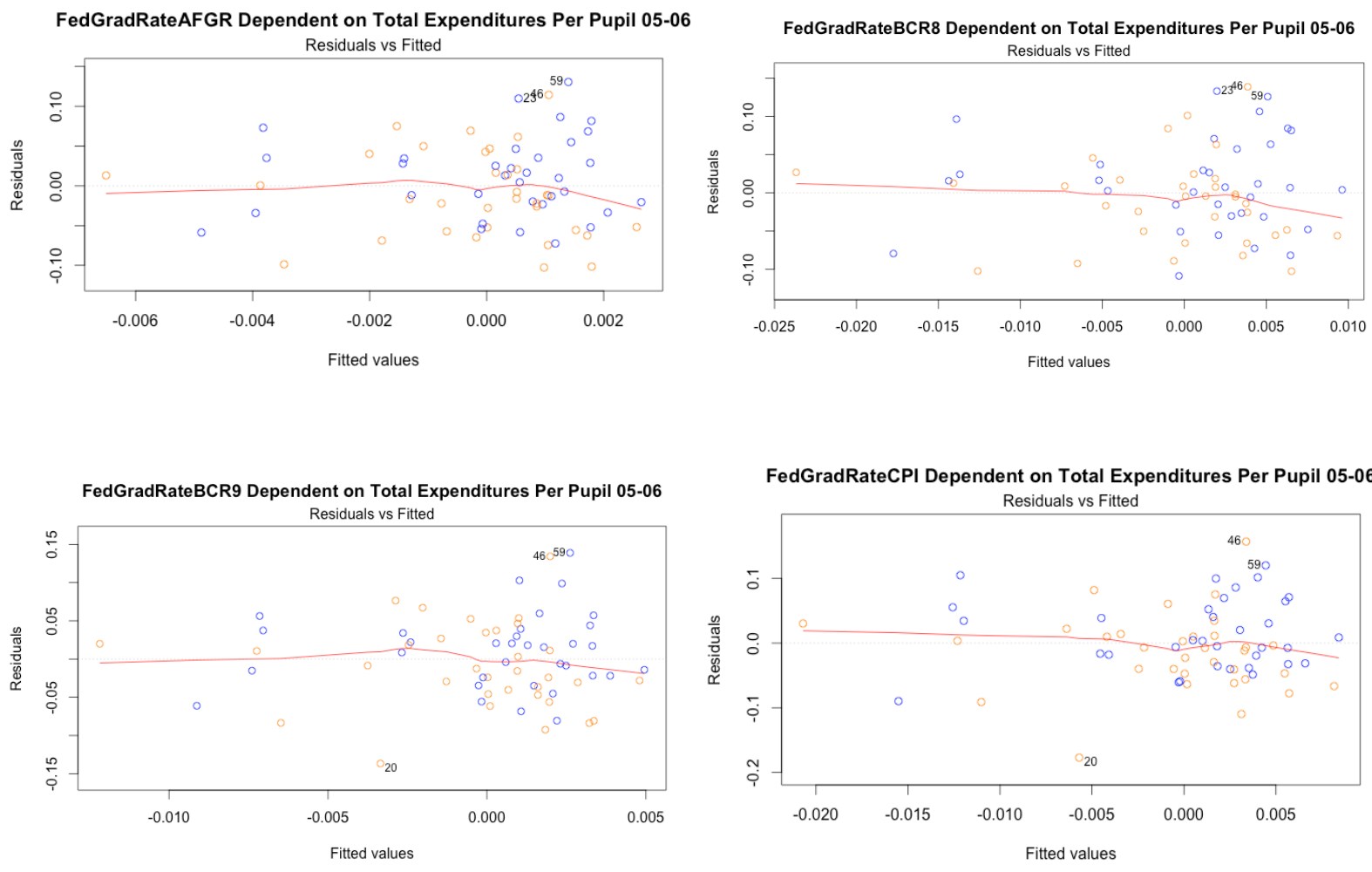
Figure 8: Graphic Representation of the Four Comparative Linear Model Residuals against Race/Ethnicity
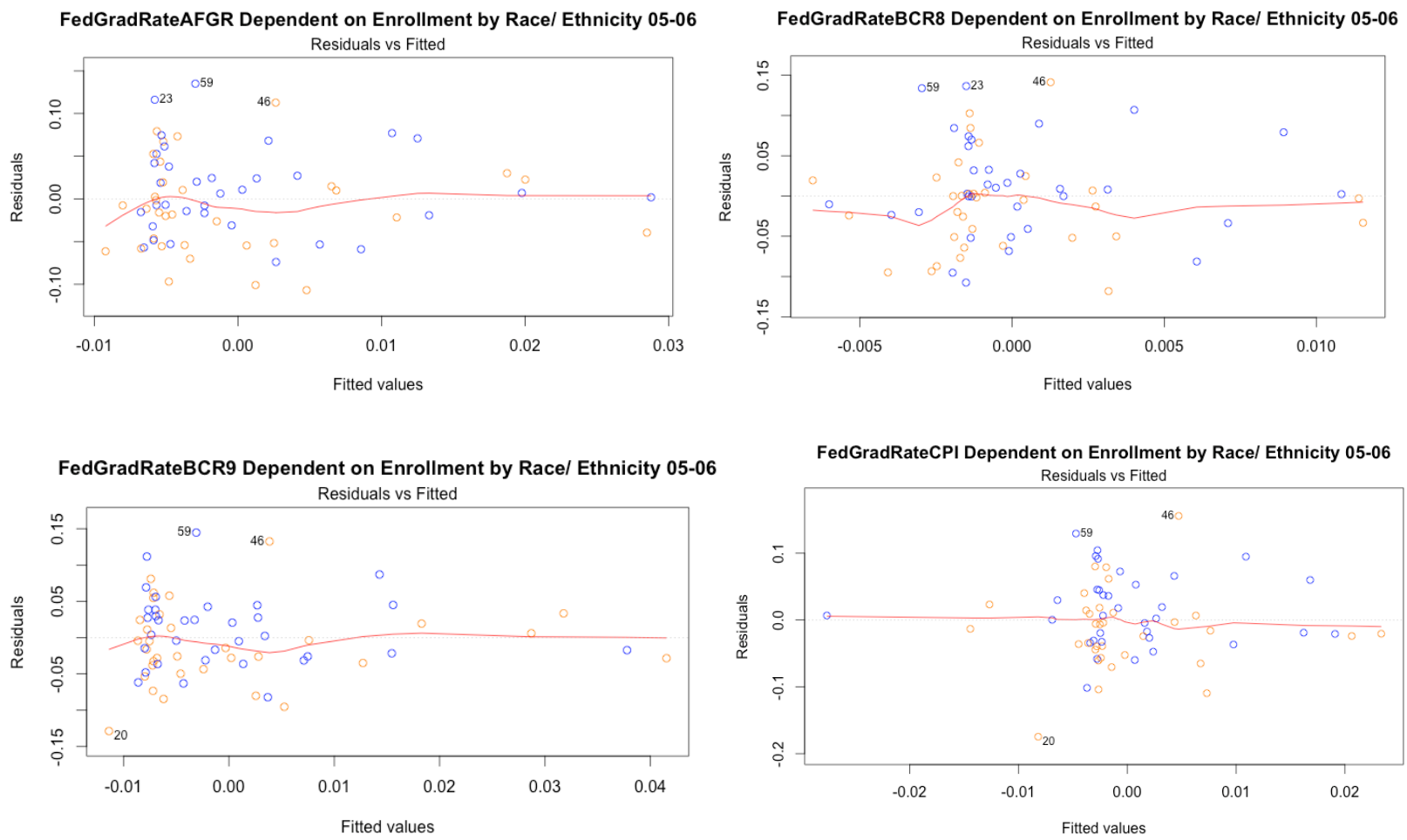

Figure 9 and Figure 10 indicate the linear model is skewed toward relatively large $\mathrm{x}$-values but may need adjustments for relatively small x-values. 
Martinez \& Dorn: Swamping errors: A Florida postmortem for high school graduation rate proxies

Figure 9: Graphic Representation of the Four Comparative Linear Model Residuals against Local Revenue Per Pupil
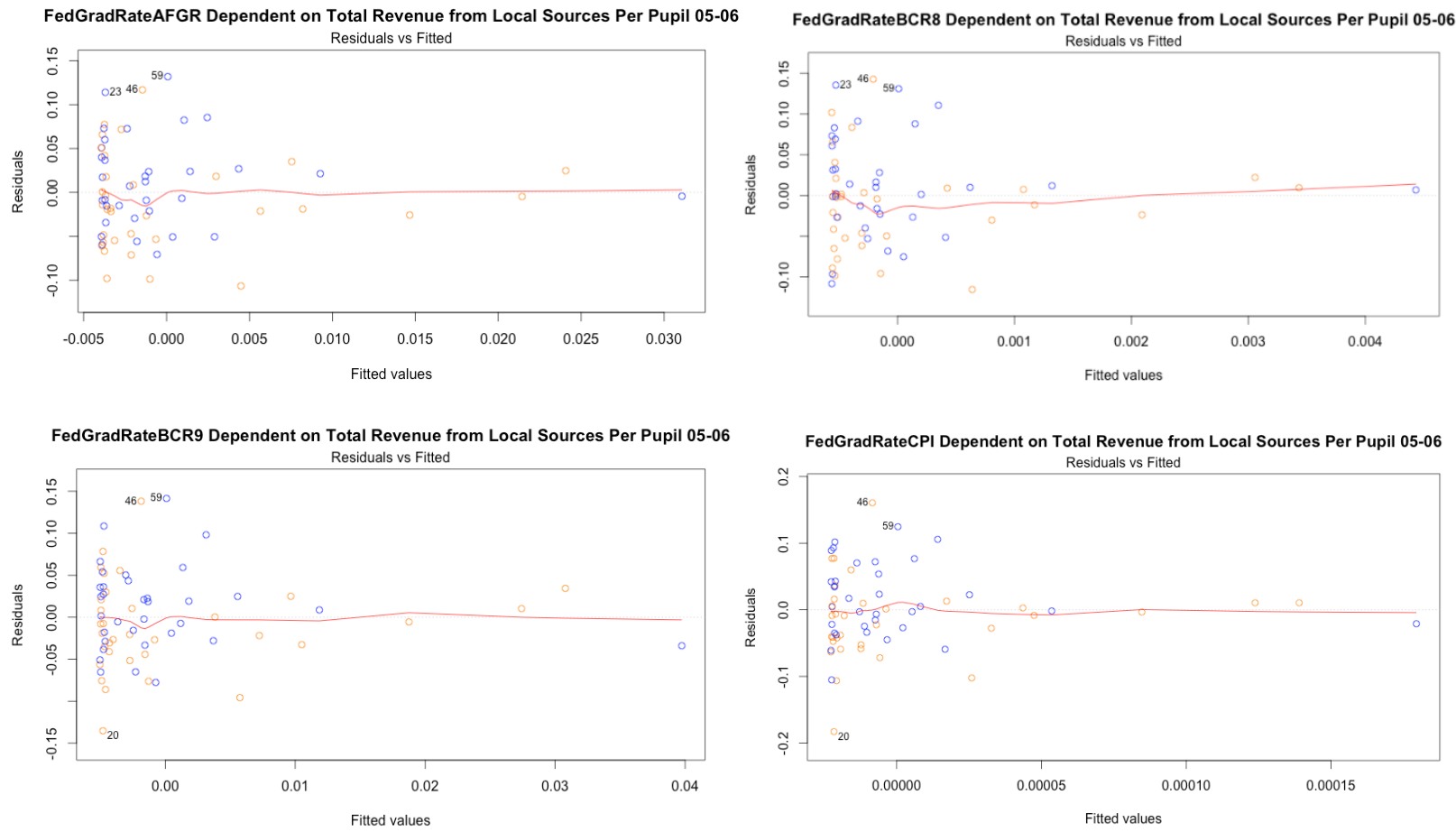
Figure 10: Graphic Representation of the Four Comparative Linear Model Residuals against Poverty Tax Revenue Per Pupil
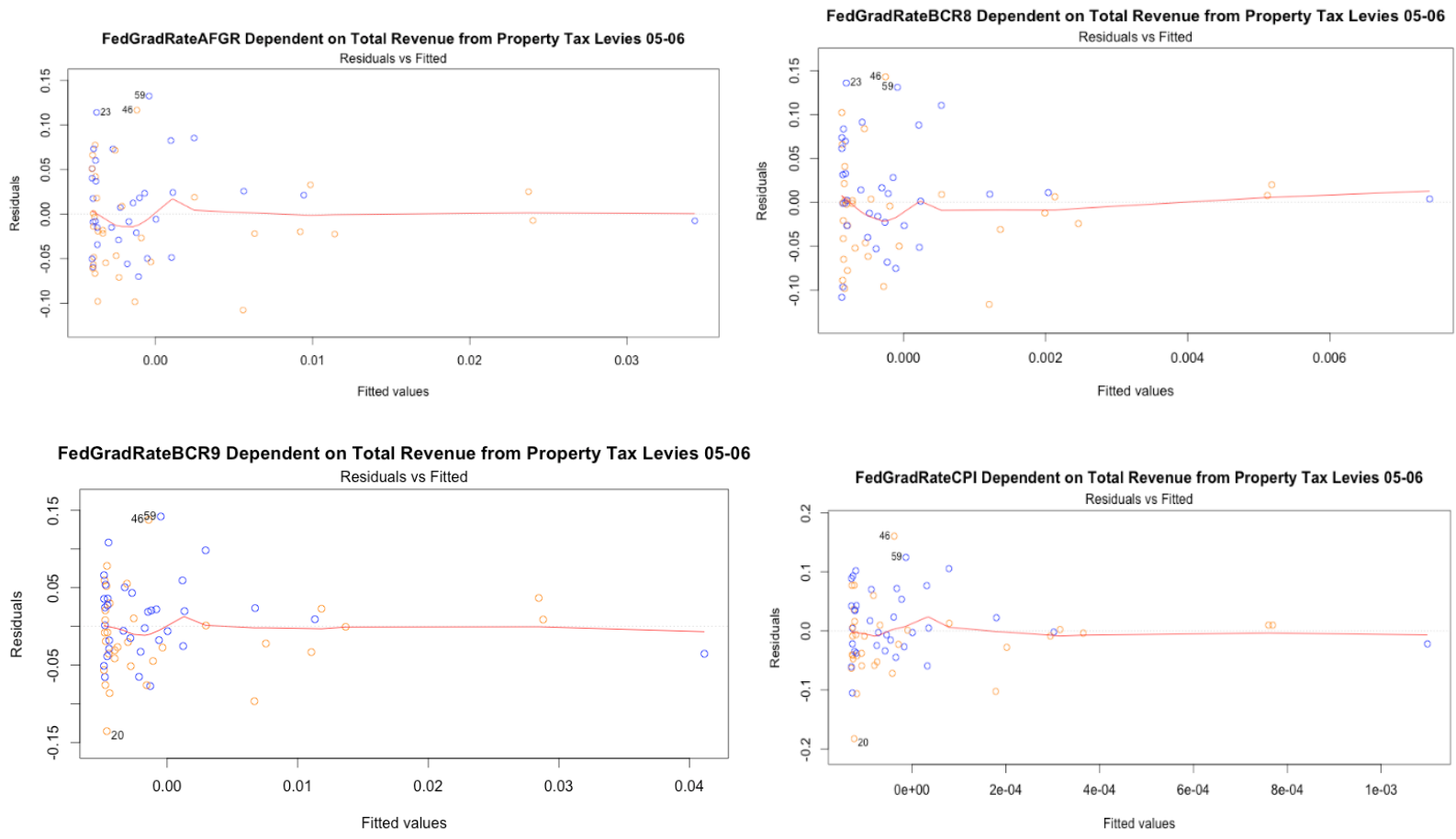

\section{Caveats}

There are some caveats to this analysis, in addition to the limitations of the individual measures noted above in Methods. The analysis does not account for the autocorrelation that should result substantively from successive cohorts in the same counties (with similar educational conditions and overlapping years of experience in high school). Nor does this paper address the autocorrelation as an artifact contained within the measures: For example, for any county and year, CPI ( $t$ ) has a set of three enrollment data points in common with both CPI ( $t-1)$ or CPI $(t+1)$. A time-series analysis is appropriate for analyzing the federal graduation rate across years but is beyond the scope of this paper.

Other limitations come from the use of a single state's data. One advantage of using Florida data is the retroactive publication of multiple years of ACGR data by county-level system. A second is the relative stability of district-level data when the district is a county. And yet the use of Florida data is a limitation: the extreme values displayed in Table 1 suggest misreporting. On the other hand, there is no guarantee that other states would have lower levels of misreporting.

\section{Discussion}

The weak relationship between graduation proxies and ACGR is a lesson in measuring graduation and the tradeoffs between practical solutions and probabilistically accurate calculations. Furthermore, concerns over measurement insufficiencies indicated through this analysis should give us pause about our reliance on insensitive measures to inform best practices that increase 
graduation. This is especially true for application in marginalized communities ignored by inadequate measures and indifferent bureaucracies (Ladson-Billings, 2006; Orfield, Losen, Wald, \& Swanson, 2004). Our analysis indicates the graduation numbers reported nationally using proxies are historically inaccurate, incapable of measuring fine-grained distinctions among districts the size of Florida's, let alone small districts and individual schools, which overlook students with higher degrees of need.

Difficulties approximating high school graduation is a sobering abject lesson in education data, privacy, and public accountability. It appears there was no plausibly accurate proxy using administrative data. An objective observer may ask why developers of proposed proxies didn't attempt to validate their measures with longitudinal data available in a few jurisdictions. Such validation with better records would have guarded researchers against overenthusiastic claims as to their utility. The discussion over graduation metrics should provoke a deeper evaluation of other accountability measures and their long-term risks. One should not search for measures of success in the tightest of vacuums, without data available for appropriate pilots, contextual evidence, recommendations, or resources necessary to reduce the persistent national achievement and attainment gaps that exist in education.

\section{Implications for Practice}

This research highlights the level of nuance the current federal rate incorporates and the difficulty in obtaining a measure that is as close to infallible as possible. More accurate calculations may require a level of invasiveness the national educational landscape may be unwilling to incorporate, but without it, districts may go without the necessary information to curb dropout rates. The most fundamental message for practitioners and policymakers alike is to recognize these measures of graduation are proxies and should, as with all purely quantitative measures, be recognized as containing only calculations as sufficient as are possible at the time of measurement. No one measure can incorporate all the relationships imbedded within schools and the successes these relationships create and thus critically conscious leaders must view these metrics through a critical lens.

Critically conscious leaders must explicitly link suggested actions to measured findings (Stage \& Wells, 2014). The ability for practitioners to stay informed, and create educational transformation requires a critical view on data and measurement, and the limitations of both (Khalifa, Dunba, \& Douglasb, 2013). For instance, and specific to Florida, graduation rates are steadily climbing but the fidelity of these increases is questionable considered against possible data and measurement inaccuracies (Rado, 2019). Seemingly Florida has excluded specific students from their graduation rate calculations, thus overpredicting their graduation rates (Rado, 2019). While on the surface increased graduation seems positive, underpredicting attrition may mask structural inequities that exist within the system which exclude certain students from fully participating in the educational pipeline. If these students are masked in the data, then practitioners are unable to create solutions that can mediate inequities. Negating a critical lens can also help mask racialized inequities as well (Khalifa, Jennings, Briscoe, Oleszweski, \& Abdi, 2014). Florida exhibits persistent racialized graduation gaps (Florida Department of Education, 2018). Critically conscious leaders must stay 
informed of graduation stratification in order to effectively target solutions that mediate attrition for those students most in need.

Finally, equity minded stakeholders should continue to engage in practical conversations about the utility of metrification and its use to degrade, and not improve, public education (Webb, Briscoe, \& Mussman, 2009). The dominant narrative of the dropout factory further exacerbated challenges within schools in need of greater resources. Stakeholders have the power however to influence the negative political discourse by using these measures as an indicator of what types of resources are necessary in order to obtain the desired result. The false narrative of the dropout factory is tied to weak calculations, and thus stakeholders must implicate legislative fiscal responsibility as a precursor to implementing programs of improvement. In order to create impactful change, those stakeholders most involved in the process (i.e., students, parents, teachers, school level administrators) require the necessary resources to create that change.

\section{Implications for Educational Leadership}

School leaders have been tasked with improving their educational setting through data-driven solutions (Mandinich \& Honey, 2008). The school leader plays a formative role in how data is used, and how it informs critically conscious, culturally responsive, solutions (Khalifa \& Gooden, 2016; Wayman, 2005; Young, 2006). From a practical standpoint, school leaders have a responsibility to establish efforts for data informed decisions. The school leader must set equity focused agendas so the data can help mediate inequities, instead of reaffirm deficit ideologies (Datnow \& Greene, 2017; Santamaría \& Jean-Marie, 2014). In order to engage in this process, a school leader must work within a paradigm of critical consciousness (McKenzie et. al., 2008; Shields, 2010). This can also help inform how the process of measurement is developed including what types of data are valued. For instance, the use of equity audits can help inform equitable practices against purely quantitative data (Skrla, McKenzie, \& Scheurich, 2009). Leaders must also provide learning opportunities for their staff, and model effective data use (Levin \& Datnow, 2012). In this manner, critically conscious, data informed, school leaders can confront their specific educational challenges as illustrative of a problematic educational structure and help their staff engage in consciousness raising through data, in order to mediate ineffective policy. Ultimately, leaders can work within the structure of mandated accountability, and take a critical role in dismantling structural inequities. The ability to engage in this type of work however requires a multi-pronged perspective that begins from a culturally responsive critical lens (Dantley, 2003).

\section{Implications for Policy}

The policy relevance of this study is drawn not only from those concerns over metrification in education but concerns directly related to the reliability of past standards to inform positive discourse, not simply critique without solution. First and foremost, impactful community minded solutions begin from understanding those factors related to social constructs which create educational opportunity gaps embodied in achievement gaps. Without some remedy for social disparity, even the best laid plans of equity minded stakeholders will lead toward only moderate gains in achievement (Dorn, 1996; Frank, 1990). 
Policy toward decreasing the graduation gap must include measures that incorporate data beyond cohort counts. Graduation, and to a larger extent all achievement metrics, must incorporate student centered data driven by social/ emotional cognitive support and the availability of this support within the educational pipeline (Zaff et. al., 2016).

In order to curb graduation gaps, schools must be willing to integrate strategies for assisted learning beyond the scope of individualized educational plans. These integrated strategies should be embedded in the fabric of the school, available to all students, of all cognitive abilities (Calhoon, Al Otaiba, Greenberg, King \& Avalos, 2006; De Witte, Cabus, Thyssen, Groot, \& Van Den Brink, 2013). These strategies must sustain learning not as a supplement, but as an integral part of the learning process. They must have clear objectives that help mitigate learning opportunity gaps which lead to achievement gaps, and must include nuances of cultural awareness (Darling, 2005; Orthner, Cook, Rose, \& Randolph, 2002; Rothstein, 2013).

Schools must adapt to the changing needs of students (Greene, 2019; Swadener \& Lubeck, 1995). Currently schools to often force students to adapt in a manner that is holistically restrictive. School leaders must be willing to change the policy order of operation. Students require guidance, but draconian policies stripping personal agency disconnect students from the learning process. Overly restrictive policies work to subvert changes in personal ontology in lieu of helping young minds through the process of change. This intersects with an earlier implication: incorporating student centered data.

Along with changing needs of students, schools must be willing to adapt to changes in demography within, in order to create opportunities for all students to learn. Cultural competence, diverse identities, diver languages, and diverse social practices add to the nuances of the school. They add to the peer experience and should be encouraged by policies and practices within the school. These competencies must be engrained in the curriculum, and pedagogy (Maldonado Torres, 2009). This awareness may help teachers create support structures within the school for diverse students (Maldonado Torres, 2009). Finally, teachers require time, and opportunities to learn, which lead to sustained policy implementation that can increase graduation rates for marginalized students. Thus ultimately, teachers require resources in order to help sustain structures of improvement (Archibald, Coggshall, Croft, \& Goe, 2011; Demonte, 2013).

\section{Lessons for Future Research and Practice}

Moving forward, policymakers must continue to consider the effectiveness of graduation rate proxies to highlight schools containing the greatest need, instead of placing blame or defining those with the greatest need as failing. Creating foundational solutions to remedy drop-out must include accurate identification of graduation in order to drive school level resources toward those districts with the most need who often educate higher proportions of families in poverty and other vulnerable populations. This includes possible changes in methodology to incorporate recursive analysis and identification based on probability distributions (e.g. Bayesian Analysis), moving away from frequentist measures.

For instance, Goenner and Snaith (2004) used Bayesian analysis to estimate higher education graduation-rates. Goenner and Snaith's measurement exploited the covariate relationships between 
student level variables and graduation rates. Solutions may also include the use of advanced technology through machine learning. Delen (2010) used an ensemble approach to measure and predict graduation. Delen found that an ensemble approach had greater reliability than individual models. Effective measurement also includes localized information with the potential to create impactful solutions. As mentioned above these include school engagement, emotional/ cognitive student support, and academic support (Appleton, Christenson, \& Furlong, 2008; Wang \& Holcombe 2010; Zaff et. al., 2016). Finally, in order to effectively address graduation gaps, stakeholders must look into the social constructs of achievement, let go of the assumptive racial impartiality of measurement, and data, and confront those structures which lead to gaps (Gillborn, 2010; Ladson-Billings \& Tate, 1995). In order to address the symptom, we must continue to address the obstacles that lead toward disparity (Rumberger \& Lim, 2008).

\section{Conclusion}

This paper compared the AFGR, BCR-8, BCR-9, and CPI with the new federal adjusted-cohortbased graduation rate (ACGR) in order to focus attention on anomalous calculation differences that may have negatively impacted those schools with low graduation numbers. It showed previous proxies were never capable of measuring small differences in attainment patterns. At best previous measures could identify dropout factories but would reliably identify anything smaller than gross drop-out differences. These types of measures, to accurately predict, and determine true success is best left to school and classroom level data, sensitive enough to capture those slight markers of success that make a difference in a student's life. The feasibility of this may occur once concerns over privacy are at least nationally diminished. For now, policymakers and pundits should focus on those resources necessary to curb drop-out, especially in districts with a higher population of families living in poverty. Finally, without these necessary changes, there may continue to be significant political pressure to measure what is present, instead of focus on what is possible.

\section{References}

Aguilar, S. J. (2018). Learning analytics: At the nexus of big data, digital innovation, and social justice in education. TechTrends, 62(1), 37-45.

Appleton, J. J., Christenson, S. L., \& Furlong, M. J. (2008). Student engagement with school: Critical conceptual and methodological issues of the construct. Psychology in the Schools, 45(5), 369-386.

Archibald, S., Coggshall, J. G., Croft, A., \& Goe, L. (2011). High-quality professional development for all teachers: Effectively allocating resources. Research \& Policy Brief. Washington, DC: National Comprehensive Center for Teacher Quality.

Atwell, M. N., Balfanz, R., Bridgeland, J., \& Ingram, E. (2019). Building a grad nation: Progress and challenge in raising high school graduation rates. Baltimore, MD: Civic Enterprises Everyone Graduates Center at the School of Education at Johns Hopkins University.

Balfanz, R., \& Legters, N. (2004). Locating the dropout crisis: Which high schools produce the nation's dropouts? Where are they located? Who attends them? Center for Research on the Education of Students Placed at Risk. Retrieved from http://new.every1graduates.org/ locating-the-dropout-crisis-full-report/

Balfanz, R., Legters, N., West, T. C., \& Weber, L. M. (2007). Are NCLB's measures, incentives, and improvement strategies the right ones for the nation's low-performing high schools? American Educational Research Journal, 44(3), 559-593.

Biesta, G. J. (2015). Good education in an age of measurement: Ethics, politics, democracy. Boulder, CO: Paradigm Publishers.

Blalock, H. M. (1982). Conceptualization and measurement in the social sciences. Thousand Oaks, CA: SAGE Publications, Inc. 
Borden, V. M., \& Young, J. W. (2008). Measurement validity and accountability for student learning. New Directions for Institutional Research, 2008(1), 19-37.

Boyd, D. M. (2014.) It's complicated: The social lives of networked teens. New Haven, CT: Yale University Press.

Calhoon, M. B., Al Otaiba, S., Greenberg, D., King, A., \& Avalos, A. (2006). Improving reading skills in predominantly Hispanic title 1 first-grade classrooms: The promise of peer-assisted learning strategies. Learning disabilities research \& Practice, 21(4), 261-272.

Carpenter, B. W. (2011). Developing turnaround leadership: Pragmatic guides and contextually specific lessons from the field. Journal of Education for Students Placed at Risk (JESPAR), 16(4), 292-298.

Carpenter, D. M., \& Ramirez, A. (2007). More than one gap: Dropout rate gaps between and among Black, Hispanic, and White students. Journal of Advanced Academics, 19(1), 32-64.

Chapman, C., Laird, J., Ifill, N., and KewalRamani, A. (2011). Trends in high school dropout and completion rates in the United States: 1972-2009 (NCES 2012-006). U.S. Department of Education. Washington, DC: National Center for Education Statistics. Retrieved from http://nces.ed.gov/pubsearch

Covarrubias, A. (2011). Quantitative intersectionality: A critical race analysis of the Chicana/o educational pipeline. Journal of Latinos and Education, 10(2), 86-105.

Cronbach, L. J. (1988). Five perspectives on validity argument. In H. Wainer \& H. Braun (eds.), Test Validity. Mahwah, NJ: Erlbaum.

Dantley, M. E. (2003). Purpose-driven leadership: The spiritual imperative to guiding schools beyond high-stakes testing and minimum proficiency. Education and Urban Society, 35(3), 273-291.

Darling, D. (2005). Improving minority student achievement by making cultural connections. Middle School Journal, 36(5), 46-50.

Datnow, A., Greene, J. C., \& Gannon-Slater, N. (2017). Data use for equity: Implications for teaching, leadership, and policy. Journal of Educational Administration, 55(4), 354-360.

Delen, D. (2010). A comparative analysis of machine learning techniques for student retention management. Decision Support Systems, 49(4), 498-506.

DeLong, J. B., Goldin, C., \& Katz, L. F. (2003). Sustaining U.S. economic growth. In Aaron et. al. (Eds.). Agenda for the Nation (pp. 17-60). Washington, DC: The Brookings Institution Press.

DeMonte, J. (2013). High-quality professional development for teachers: Supporting teacher training to improve student learning. Washington, DC: Center for American Progress.

DePaoli, J. L., Fox, J. H., Ingram, E. S., Maushard, M., Bridgeland, J. M., \& Balfanz, R. (2015). Building a grad nation: Progress and challenges in ending the high school dropout epidemic. Baltimore, MD: Civic Enterprises Everyone Graduates Center at the School of Education at Johns Hopkins University.

De Witte, K., Cabus, S., Thyssen, G., Groot, W., \& Van Den Brink, H. M. (2013). A critical review of the literature on school dropout. Educational Research Review, 10, 13-28.

Dillard, C. B. (2000). The substance of things hoped for, the evidence of things not seen: Examining an endarkened feminist epistemology in educational research and leadership. International Journal of Qualitative Studies in Education, 13(6), 661-681.

Dorn, S. (1996). Creating the dropout: An institutional and social history of school failure. Westport, CT: Praeger.

Ebel, R. L. \& Frisbie, D. A. (1991). Essentials of educational measurement. Englewood Cliffs, NJ: Prentice Hall.

Elliot, A. J., \& Murayama, K. (2008). On the measurement of achievement goals: Critique, illustration, and application. Journal of Educational Psychology, 100(3), 613.

Every Student Succeeds (ESSA) Act of 2015, Pub. L. No. 114-95 § 114 Stat. 1177 (2015-2016).

Florida Education Information \& Accountability Services. (2015). Florida's federal high school graduation rates, 1998-2014. Tallahassee, FL: Florida Department of Education. Retrieved from http://www.fldoe.org/accountability/data-sys/edu-info-accountability-services/pk-12-public-school-datapubs-reports/archive.stml

Fowler, D. J., \& Brown, K. (2018). Data-driven decisions: Using equity theory to highlight implications for underserved students. AASA Journal of Scholarship \& Practice, 14(4), 18-28.

Frattura, E. M., \& Capper, C. A. (2007). Leading for social justice: Transforming schools for all learners. Thousand Oaks, CA: Corwin Press.

Garcia, N. M., \& Mayorga, O. J. (2018). The threat of unexamined secondary data: A critical race transformative convergent mixed methods. Race Ethnicity and Education, 21(2), 231-252.

Garcia, N. M., Lopez, N., \& Velez, V. N. (2018). QuantCrit: Rectifying quantitative methods through critical race theory. Race Ethnicity and Education, 21(2), 149-157.

Gillborn, D. (2010). The colour of numbers: Surveys, statistics and deficit-thinking about race and class. Journal of Education Policy, 25(2), 253-276. 
Gillborn, D., Warmington, P., \& Demack, S. (2018). QuantCrit: Education, policy, 'Big Data' and principles for a critical race theory of statistics. Race Ethnicity and Education, 21(2), 158-179.

Goenner, C. F., \& Snaith, S. M. (2004). Predicting graduation rates: An analysis of student and institutional factors at doctoral universities. Journal of College Student Retention: Research, Theory \& Practice, 5(4), 409-420.

Goldin, C. D., \& Katz, L. F. (2009). The race between education and technology. Cambridge, MA: Belknap Press of Harvard University Press.

Greene, M. (2019). Best practices for addressing the achievement gap for Hispanic Oelementary students (Doctoral dissertation). Available from Brandman University Digital Repositories. (No 232)

Greene, J. P., \& Forster, G. (2003). Public high school graduation and college readiness rates in the United States (No. 3). New York, NY: Center for Civic Innovation of the Manhattan Institute for Policy Research. Retrieved from http://www.manhattan-institute.org/pdf/ewp_08.pdf

Haberman, M. (2000). Urban schools: Day camps or custodial centers? Phi Delta Kappan, 82(3), 203-208.

Heckman, J. J., \& LaFontaine, P. A. (2010). The American high school graduation rate: Trends and levels. The review of economics and statistics, 92(2), 244-262.

Horsford, S. D., \& Sampson, C. (2013). The Las Vegas Promise Neighborhood Initiative: A community-based approach to improving educational opportunity \& achievement. Las Vegas, NV: The Lincy Institute.

Improving the Academic Achievement of the Disadvantaged (Title I), 34 C.F.R. $§ 200$ (2008).

Kaufman, P., Alt, M. N., \& Chapman, C. D. (2004). Dropout rates in the United States: 2001 (NCES 2005-046). Washington, DC: National Center for Education Statistics. Retrieved from https://nces.ed.gov/pubs2005/2005046.pdf

Kelly, A. E., \& Seppälä, M. (2016). Changing policies concerning student privacy and ethics in online education. International Journal of Information and Education Technology, 6(8), 652-655.

Khalifa, M., Dunbar, C., \& Douglas, T. R. (2013). Derrick Bell, CRT, and educational leadership 1995present. Race Ethnicity and Education, 16(4), 489-513.

Khalifa, M. A., Gooden, M. A., \& Davis, J. E. (2016). Culturally responsive school leadership: A synthesis of the literature. Review of Educational Research, 86(4), 1272-1311.

Khalifa, M. A., Jennings, M. E., Briscoe, F., Oleszweski, A. M., \& Abdi, N. (2014). Racism? Administrative and community perspectives in data-driven decision making: Systemic perspectives versus technical-rational perspectives. Urban Education, 49(2), 147-181.

Klein, A. (2015, November 30). ESEA reauthorization: The Every Student Succeeds Act explained [Web blog post]. Retrieved from: http://blogs.edweek.org/edweek/campaign-k12/2015/11/esea reauthorization the every.html

Ladson-Billings, G. (2006). From the achievement gap to the education debt: Understanding achievement in US schools. Educational Researcher, 35(7), 3-12.

Ladson-Billings, G., \& Tate, W. F. (1995). Toward a critical race theory of education. Teachers College Record, 97(1), 47-68.

Lane, J., Stodden, V., Bender, S., \& Nissenbaum, H. (Eds.). (2014). Privacy, big data, and the public good: Frameworks for engagement. New York, NY: Cambridge University Press.

Lapenta, G., \& Jørgensen, R. (2015). Youth, privacy and online media: Framing the right to privacy in public policy-making. First Monday, 20(3). doi: 10.5210/fm.v20i3.5568

Lee, T., Cornell, D., Gregory, A., \& Fan, X. (2011). High suspension schools and dropout rates for black and white students. Education and Treatment of Children, 34(2), 167-192.

Levin, H. M. (2009). The economic payoff to investing in educational justice. Educational Researcher, 38(1), 5-20.

Levin, J. A., \& Datnow, A. (2012). The principal role in data-driven decision making: Using case-study data to develop multi-mediator models of educational reform. School Effectiveness and School Improvement, 23(2), 179-201.

López, N., Erwin, C., Binder, M., \& Chavez, M. J. (2018). Making the invisible visible: Advancing quantitative methods in higher education using critical race theory and intersectionality. Race Ethnicity and Education, 21(2), 180-207.

Maguire, M. (2019). Equality and justice in education policy. Journal of Education Policy, 34(3), 299-301.

Maldonado Torres, S. E. (2009). Identifying Latinos' learning styles and demographic factors to support their learning performance (Doctoral dissertation). Available from ProQuest Dissertation and Theses database. (UMI No 3350588) 
McFarland, J., Hussar, B., Zhang, J., Wang, X., Wang, K., Hein, S., . . Barmer, A. (2019). The Condition of Education 2019 (NCES 2019-144). U.S. Department of Education. Washington, DC: National Center for Education Statistics. Retrieved from https://nces.ed.gov/ pubsearch/pubsinfo. asp?pubid=2019144

McKenzie, K. B., Christman, D., Hernandez, F., Fierro, E., Capper, C. A., Dantley, M., ... Scheurich, J. J. (2008). From the field: A proposal for educating leaders for social justice. Educational Administration Quarterly, 44(1), 111-138.

Miao, J., \& Haney, W. (2004). High school graduation rates: Alternative methods and implications. Education Policy Analysis Archives, 12(55). doi: 10.14507/epaa.v12n55.2004

Milner IV, H. R. (2007). Race, culture, and researcher positionality: Working through dangers seen, unseen, and unforeseen. Educational Researcher, 36(7), 388-400.

Murnane, R. J. (2013). U.S. high school graduation rates: Patterns and explanations. Journal of Economic Literature, 51(2), 370-422.

National Center for Education Statistics. (2015). Elementary and secondary information system. Common Core of Data. Retrieved from http://nces.ed.gov/ccd/elsi/tableGenerator.aspx

No Child Left Behind (NCLB) Act of 2001, 20 U.S.C. $\$ 6319$ (2002).

Nover, A., Godsay, S., Kirby, E. H., \& Kawashima-Ginsberg, K. (2010). Electoral engagement and college experience. Medford, MA: The Center for Information \& Research on Civic Learning and Engagement. Retrieved from http://civicyouth.org/PopUps/FactSheets/FS_08_Educ_Voting.pdf

Orfield, G., Losen, D., Wald, J., \& Swanson, C. B. (2004). Losing our future: How minority youth are being left behind by the graduation rate crisis. Cambridge, MA: The Civil Rights Project, Harvard University.

Orthner, D. K., Cook, P. G., Rose, R. A., \& Randolph, K. (2002). Welfare reform, poverty, and children's performance in school: Challenges for the school community. Children \& Schools, 24(2), 105-121.

Pinkus, L. (2006). Who's counted? Who's counting? Understanding high school graduation rates. Washington, DC: Alliance for Excellent Education. Retrieved from http://dropoutprevention.org/wpcontent/uploads/2015/05/Understanding_High_School_Graduation_Rates.pdf

Rado, D. (2019, January 25). Are impressive graduation rates in FL for real? State calculations eliminate thousands of kids, boosting results. Florida Phoenix. Retrieved from https://www.floridaphoenix.com/2019/01/25/areimpressive-graduation-rates-in-fl-for-real-state-calculations-eliminate-thousands-of-kids-boosting-results/

Rothstein, R. (2013). Why children from lower socioeconomic classes, on average, have lower academic achievement than middle-class children. In P. L. Carter \& K. G. Welner (Eds.). Closing the opportunity gap: What America must do to give every child an even chance (61-74). New York, NY: Oxford University Press.

Rumberger, R. W. (1987). High school dropouts: A review of issues and evidence. Review of Educational Research, 57(2), 101-121.

Rumberger, R. W. (2011). Dropping out: Why students drop out of high school and what can be done about it. Cambridge, MA: Harvard University Press.

Rumberger, R. W., \& Lim, S. A. (2008). Why students drop out of school: A review of 25 years of research. Santa Barbara, CA: California Dropout Research Project. Retrieved from http://www.slocounty.ca.gov/Assets/CSN/PDF/Flyer+-+Why+students+drop+out.pdf

Santamaría, L. J., \& Jean-Marie, G. (2014). Cross-cultural dimensions of applied, critical, and transformational leadership: Women principals advancing social justice and educational equity. Cambridge Journal of Education, 44(3), 333-360.

Seastrom, M., Chapman, C., Stillwell, R., McGrath, D., Peltola, P., Dinkes, R., \& Xu, Z. (2006). User's guide to computing high school graduation rates, volume 2: Technical evaluation of proxy graduation indicators (NCES 2006-605). Washington, DC: National Center for Education Statistics.

Shadish, W. R., Cook, T., \& Campbell, D. (2002). Experimental and Quasi-Experimental Designs for Generalized Causal Inference. New York, NY: Houghton Mifflin Company.

Shields, C. M. (2010). Transformative leadership: Working for equity in diverse contexts. Educational administration quarterly, 46(4), 558-589.

Skrla, L., McKenzie, K. B., \& Scheurich, J. J. (Eds.). (2009). Using equity audits to create equitable and excellent schools. Thousand Oaks, CA: Corwin Press.

Stage, F. K., \& Wells, R. S. (2014). Critical quantitative inquiry in context. New Directions for Institutional Research, 2013(158), 1-7.

Stanfield, J. (1995). The myth of race and the human sciences. The Journal of Negro Education, 64(3), 218-231. 
Stetser, M. C., \& Stillwell, R. (2014). Public high school four-year on-time graduation rates and event dropout rates: School years 2010-11 and 2011-12, first look (NCES 2014-391). Washington, DC: National Center for Education Statistics. Retrieved from http://files.eric.ed.gov/fulltext/ED544798.pdf

Stillwell, R., \& Sable, J. (2013). Public school graduates and dropouts from the Common Core of Data: School year 2009-10: first look (NCES 2013-309). Washington, DC: National Center for Education Statistics. Retrieved from http://nces.ed.gov/pubs2013/2013309.pdf

Stovall, D. (2013). Against the politics of desperation: Educational justice, critical race theory, and Chicago school reform. Critical Studies in Education, 54(1), 33-43.

Swadener, B. B., \& Lubeck, S. (Eds.). (1995). Children and families "at promise": Deconstructing the discourse of risk. Albany, NY: State University of New York Press.

Swanson, C. B. (2004). Who graduates? Who doesn't? A statistical portrait of public high school graduation, class of 2001. Washington, DC: Education Policy Center of the Urban Policy Institute. Retrieved from http://www.urban.org/sites/default/files/alfresco/publication-pdfs/410934-Who-Graduates-Who-Doesn-t.PDF

Swanson, C. B., \& Chaplin, D. (2003). Counting high school graduates when graduates count: Measuring graduation rates under the high stakes of NCLB. Washington, DC: Education Policy Center of the Urban Policy Institute. Retrieved from http://www.urban.org/sites/default/files/alfresco/publication-pdfs/410641Counting-High-School-Graduates-when-Graduates-Count.PDF

Task Force on State High School Graduation Data. (2005). Graduation counts: A report of the National Governors Association Task Force on state high school graduation data. Washington, DC: National Governors Association. Retrieved from http://www.nga.org/files/live/sites/NGA/files/pdf/0507GRAD.PDF

United State Department of Education (USDOE). (2017). Every Student Succeeds Act high school graduation rate non-regulatory guidance. Washington, DC: Author.

Wang, M. T., \& Holcombe, R. (2010). Adolescents' perceptions of school environment, engagement, and academic achievement in middle school. American Educational Research Journal, 47(3), 633-662.

Wayman, J. C. (2005). Involving teachers in data driven decision making: Using computer data systems to support teacher inquiry and reflection. Journal of Education for Students Placed at Risk, 10(3), 295-308.

Webb, E. L. (2016). Getting students to graduation: The relationship between academic interventions and graduation rates for failing high school students (Unpublished master's thesis). Washington, DC: Georgetown University.

Webb, T., Briscoe, F., \& Mussman, M. (2009). Preparing teachers to resist the neoliberal panopticon. Educational Foundations, 23(3-4), 3-18.

Young, V. M. (2006). Teacher's use of data: Loose coupling, agenda setting, and team norms. American Journal of Education, 112(4), 521-548.

Zaff, J. F., Aasland, K., McDermott, E., Carvalho, A., Joseph, P., \& Pufall-Jones, E. (2016). Exploring positive youth development among young people who leave school without graduating high school: A focus on social and emotional competencies. Qualitative Psychology, 3(1), 26-45.

Zuberi, T. (2001). Thicker than blood: How racial statistics lie. Minneapolis, MN: University of Minnesota Press. 